\title{
RESULTS OF LABORATORY STUDIES OF GRAIN DRYING IN FLUIDIZED BED DRYER
}

\author{
Nataliya Tsyvenkova ${ }^{1}$, Inna Nezdvetskaya ${ }^{1}$, Yaroslav Yarosh ${ }^{1}$, Viacheslav Chuba $^{2}$ \\ ${ }^{\mathrm{I}}$ Zhytomyr National Agroecological University, Ukraine; \\ ${ }^{2}$ National University of Life and Environmental Sciences of Ukraine, Ukraine \\ nataliyatsyvenkova@gmail.com, inezd@ukr.net,yaroslav.yarosh76@gmail.com,vvchuba@ukr.net
}

\begin{abstract}
A paper presents mathematical modelling and experimental results of grain drying in a dryer with pseudofluidized bed with intermittent drying media supply, working on producer gas. A system of four differential equations that interconnects the grain moisture content and temperature and drying media temperature humidity are presented. Straw and producer gas consumption for grain drying is presented. A multifactor experiment is done, where the drying media temperature, number of sections and sections blowing time are variable factors. Response surfaces are built on these data. Experimental results let us define the optimal calm period to the blow period ratio and drying media temperature that provide the highest grain moisture evaporation tempo. The obtained measurement results are in high correlation with the calculations. It illustrates that using gasifier technologies to supply grain dryers is expedient and provides high indexes of economical, energetic and ecological effectiveness, when using straw with the moisture content range of 10-30\%. Using this dryer lowers specific expenses on after harvesting post processing up to $30 \%$.
\end{abstract}

Keywords: fluidized bed, grain drying, gasifier technologies.

\section{Introduction}

In Ukraine existing drying modes in installations with periodical and continuous action do not provide substantial during quality and correspondent energy expenditures. The existing dryers have a low coefficient of productivity $(\mathrm{CoP})$ and high specific material consumption [1].

As an alternative for convectional type dryers there are dryers with pseudofluidized bed [2]. Moist product is dried in the pseudofluidized layer that is created by heated drying media provided through the distribution system maintaining a "boiling" layer in the drying chamber [3-5]. Herewith created mode mixes the product effectively that raises the heat transfer coefficient, raising the whole product volume drying effectiveness [4]. While grain is moving in the "boiling" layer through the dryer sections, the used drying media is evacuated through the system of filters and cyclones $[2 ; 6 ; 7]$. For companies that have a surplus of straw, to provide production self-sufficiency and high indexes of ecological and energy efficiency it is expedient to equip dryers with gasifiers [8;9].

Besides pros such dryers have some disadvantages. Separate grains, because of mixing, spend unequal time in the layer. As a result the grain mass can be processed unequally, that is not good especially for sowing grain. Using the gasifier as an energy supply for the dryer makes the situation even more complicated. Thus, there are sufficient achievements in the area of gasifying, especially agricultural raw material and its mixtures [10], however, there is still a problem of coordination between the thermo-technical modes of the gasifier and the dryer operation $[9 ; 11]$.

There are quite enough scientific investigations describing the drying process in the pseudofluidized layer $[3 ; 5 ; 12]$, although not all of them represent modelling of drying grain material, especially of sowing grain, when feeding the grain dryer with producer gas. Systematization of the grain and bean drying process (not considering the drying methods) modelling methods is rather complicated because of multiple factors that impact the integral effect of this process $[3 ; 4 ; 7 ; 13-20]$. Scientists tend to analyze these factors in different ways, depending on the type of the system that is investigated: grain properties, process parameters etc. [13; 16; 17]. Assumptions are reviewed (depending on the model) about the type of heat-mass transfer, separate grain movement inside the grain mass, mixing grade, type of the drying media, drying agent temperature ratio inside the grain mass and on the exit from it, the type of experimental kinetics of the process [5] and dried material heating $[3 ; 4 ; 12 ; 14-17]$.

There are a lot of interesting works about modelling complex drying processes in dryers with fluidized bed proposed by scientists from Australia [3; 4; 13], Iran [12], Latvia [16; 17], Argentina [5], Ireland [18], the U.K. [19], Germany [20]. Depending on their aim these models were developed either to optimize the existing processes or to develop a new procedure. Discrete element method and computation fluid dynamics are the most used [13]. Computation fluid dynamics method is a powerful tool for its capacity of in-depth analysis of heat exchange, mass transfer and flow in multi-component 
systems. However, it is difficult for the computation fluid dynamics method to consider the discrete nature of grains $[13 ; 15]$. This problem can be solved with the discrete element method [13; 14]. If we want to describe the processes such as mass, heat transfer in pseudofluidized layer and investigate coupled gas-particle flows, it is better to combine computation fluid dynamics models with discrete element method models [14]. This combined method gives us a possibility to generate detailed grain scale information (to describe the acting forces and trajectory of individual grains) [14]. Many scientific works demonstrated that this combined approach is effective to examine the flow and heat transfer in fluidized systems [13-15]. But every mathematical model should be proved by experiments. It is necessary to investigate the grain drying process in a dryer with pseudofluidized bed and intermittent drying media supply, working on producer gas.

\section{Materials and methods}

A mathematical model for convectional drying of grain in a pseudofludized state was developed based on the mass and thermal balance of the dried product and drying media [6]. Drying agent supply was intermittent (blowing - calm period - blowing - ...). Drying zone was divided into $n$ sections, that were blowing through in series, each one for $\tau$ seconds. Blowing was removing moisture from the surface of grain, and during the calm period moisture and heat inside the grains were redistributing [13].

We neglected the specific heat capacity temperature coefficient for dry material and water at temperatures around maximum permissible temperature of grain heating according to $[6 ; 21]$. Latent heat of evaporation $r$ that depends on the initial dried product temperature $T_{1}$ was calculated by recommendations [21]. To create a mathematical model of drying a grain product with intermittent drying media supply according to recommendations [6] such assumptions were made. It was assumed that: transportation of dried product particles in vertical direction is ideal, and temperature changes only alongside the machine ( $x$ axis) from minimum (feeding side) to maximum; drying media temperature that comes out of grain layer is equal to grain average temperature in the layer; mass transfer and heat exchange proceeds only between the drying media and the dried material; when the dried product is in the calm period, its moisture content and temperature do not change.

We obtained the following system of partial differential equations including the grain temperature $T_{1}(x, \tau)$, its moisture $W(x, \tau)$, the temperature of the drying media (air) $T_{2}(x, \tau)$ and humidity $d(x, \tau)[6 ; 16]:$

$$
\begin{gathered}
\frac{\partial W}{\partial \tau}=-k \cdot\left(W-W^{P}\right), \tau>0, \mathrm{x}>0, \\
\frac{\partial W}{\partial \tau}=-\frac{\rho_{2} \cdot \varepsilon}{10 \cdot \rho_{1}} \cdot\left(\frac{\partial d}{\partial \tau}+V_{1} \cdot \frac{\partial d}{\partial x}\right), \tau>0, \mathrm{x}>0, \\
A \cdot \frac{\partial T_{1}}{\partial \tau}+B \cdot \frac{\partial W}{\partial \tau}=\frac{\partial T_{2}}{\partial \tau}+V_{1} \cdot \frac{\partial T_{2}}{\partial x}, \tau>0, \mathrm{x}>0, \\
\lambda \frac{\partial^{2} T_{1}}{\partial x^{2}}-V_{1} \cdot D \frac{\partial T_{1}}{\partial x}-E \cdot W\left(T_{2}-\left.T_{2}\right|_{\tau=0}\right)=0, \tau>0, \mathrm{x}>0 .
\end{gathered}
$$

There:

$$
A=-\frac{D}{E \cdot \varepsilon} ; \quad B=-\frac{\rho_{1} \cdot r}{100 E \cdot \varepsilon} ; \quad D=\rho_{1} \cdot c_{1} ; \quad E=\rho_{2} \cdot c_{2},
$$

where $\quad x, \tau-$ variables of space and time.

Equilibrium moisture content $W^{P}$ was obtained from [17].

Initial and boundary conditions for the system (1) - (4) can be written in the following way. Initial conditions:

$$
T_{1}(x, 0)=T_{1}(x)=\text { const } ; \quad T_{2}(x, 0)=T_{2}(x)=\text { const } ; \quad W(x, 0)=d(x, 0)=\text { const } .
$$


$\lambda$ - effective heat conductivity coefficient of the layer in horizontal direction, $\mathrm{kJ} \cdot \mathrm{m}^{-2} \cdot \mathrm{h}^{-1} \cdot \mathrm{K}^{-1}$;

$k$ - drying coefficient, $\mathrm{h}^{-1}$;

$V_{1}$ - grain layer movement velocity along the dryer axis, $\mathrm{m} \cdot \mathrm{s}^{-1}$;

Boundary conditions:

$$
T_{1}(0, \tau)=\text { const }, \quad T_{1}(l, \tau)=\text { const } ; \quad \frac{\partial W(l, \tau)}{\partial x}=\text { const } ; \quad \frac{\partial T_{2}(0, \tau)}{\partial x}=\frac{\partial T_{2}(l, \tau)}{\partial x}=0 .
$$

where $l$ - dryer length, $\mathrm{m}$.

Equation system (1-4) analytical solution with more variables is complicated.

To solve this problem a stepped calculation method was used that was sequential (in time and space) calculation of the drying process, using the MATLAB version 6.5.

The physical and chemical properties of the dried product (wheat grain) for modelling were: bulk density $\rho_{1}=850 \mathrm{~kg} \cdot \mathrm{m}^{-3}$, specific heat capacity $c_{1}=1.55 \mathrm{~kJ} \cdot\left(\mathrm{kg} \cdot{ }^{\circ} \mathrm{K}\right)^{-1}$, dried product layer porosity $\varepsilon=0.4$. The physical and chemical properties of the drying media (air) were: specific heat capacity $c_{2}=1.01 \mathrm{~kJ} \cdot\left(\mathrm{kg} \cdot{ }^{\circ} \mathrm{K}\right)^{-1}$, density $\rho_{2}=0.89 \mathrm{~kg} \cdot \mathrm{m}^{-3}$. Specific heat of evaporation was $r=2.26 \cdot 10^{6} \mathrm{~J} \cdot \mathrm{kg}^{-1}$. Drying agent had a velocity of $V_{2}=2.5 \mathrm{~m} \cdot \mathrm{s}^{-1}$. For modelling by recommendations [6] the dried product layer height was set at $0.1 \mathrm{~m}$. The results of modelling for $T_{2}=333 \mathrm{~K}$ are given in Table 1 .

Table 1

Results of mathematical modelling of grain drying process

\begin{tabular}{|c|c|c|c|c|c|c|c|c|c|c|c|c|}
\hline \multirow{3}{*}{ 预 } & \multicolumn{3}{|c|}{$\begin{array}{c}\text { Dried product } \\
\text { temperature } T_{1},{ }^{\circ} \mathrm{K}\end{array}$} & \multicolumn{3}{|c|}{$\begin{array}{c}\text { Dried product } \\
\text { moisture } \\
\text { content } W, \%\end{array}$} & \multicolumn{3}{|c|}{$\begin{array}{c}\text { Drying media } \\
\text { temperature } T_{2},{ }^{\circ} \mathrm{K}\end{array}$} & \multicolumn{3}{|c|}{$\begin{array}{c}\text { Drying media } \\
\text { moisture content } \\
d, \mathrm{~g}^{\circ} \mathrm{kg}^{-1} \text { of d.a. }\end{array}$} \\
\hline & \multicolumn{12}{|c|}{ Blowing through time of one section $\tau, \mathrm{s}$} \\
\hline & 10 & 30 & 50 & 10 & 30 & 50 & 10 & 30 & 50 & 10 & 30 & 50 \\
\hline $\begin{array}{l}\text { at the } \\
\text { entrance }\end{array}$ & 288.0 & 288.0 & 288.0 & 19.0 & 19.0 & 19.0 & 333.0 & 333.0 & 333.0 & 11.0 & 11.0 & 11.0 \\
\hline 1 & 288.3 & 289.8 & 290.2 & 18.9 & 18.8 & 18.8 & 321.5 & 311.0 & 303.2 & 18.9 & 18.8 & 18.8 \\
\hline 2 & 288.8 & 291.7 & 292.7 & 18.7 & 18.3 & 18.2 & 321.6 & 311.1 & 304.3 & 18.8 & 18.7 & 18.6 \\
\hline 3 & 289.3 & 293.6 & 295.4 & 18.5 & 17.8 & 17.6 & 321.7 & 311.2 & 305.6 & 18.7 & 18.6 & 18.4 \\
\hline 4 & 289.8 & 295.2 & 298.1 & 18.3 & 17.4 & 17.0 & 321.8 & 311.3 & 306.9 & 18.6 & 18.5 & 18.2 \\
\hline 5 & 290.3 & 296.8 & 300.8 & 18.2 & 17.0 & 16.5 & 321.9 & 311.4 & 308.2 & 18.5 & 18.4 & 18.0 \\
\hline 6 & 290.7 & 298.3 & 303.5 & 18.1 & 16.6 & 16.0 & 322.0 & 311.6 & 309.3 & 18.4 & 18.3 & 17.9 \\
\hline 7 & 291.1 & 299.9 & 306.2 & 18.0 & 16.2 & 15.5 & 322.1 & 311.8 & 310.4 & 18.3 & 18.2 & 17.7 \\
\hline 8 & 291.5 & 301.4 & 308.7 & 17.9 & 15.8 & 15.1 & 322.2 & 313.0 & 311.6 & 18.3 & 18.1 & 17.6 \\
\hline 9 & 291.9 & 302.8 & 311.2 & 17.8 & 15.5 & 14.7 & 322.3 & 313.2 & 312.3 & 18.3 & 18.0 & 17.5 \\
\hline 10 & 292.3 & 303.9 & 313.6 & 17.7 & 15.2 & 14.3 & 322.4 & 313.4 & 313.0 & 18.2 & 17.9 & 17.4 \\
\hline 11 & 292.7 & 304.8 & 316.0 & 17.6 & 14.9 & 13.9 & 322.5 & 313.6 & 313.4 & 18.2 & 17.8 & 17.3 \\
\hline 12 & 293.1 & 305.7 & 318.3 & 17.5 & 14.6 & 13.5 & 322.6 & 313.8 & 314.0 & 18.2 & 17.7 & 17.2 \\
\hline 13 & 293.4 & 306.6 & 320.6 & 17.4 & 14.3 & 13.1 & 322.7 & 314.0 & 314.6 & 18.1 & 17.6 & 17.1 \\
\hline 14 & 293.7 & 307.1 & 322.8 & 17.3 & 14.0 & 12.7 & 322.8 & 314.3 & 315.2 & 18.1 & 17.5 & 17.0 \\
\hline 15 & 294.1 & 307.6 & 325.0 & 17.2 & 13.7 & 12.4 & 322.9 & 314.6 & 315.8 & 18.1 & 17.4 & 16.9 \\
\hline 16 & 294.3 & 308.0 & 327.2 & 17.1 & 13.5 & 12.1 & 323.0 & 315.0 & 316.4 & 18.0 & 17.3 & 16.8 \\
\hline
\end{tabular}

The results of modelling say that when the drying media temperature grows, the drying speed also grows, but grain overcomes the maximum permissible temperature the same time.

The specific straw consumption $G$ and medium hour producer gas consumption $C_{\text {gas }}$ depend a lot on the type of fuel and its moisture content:

$$
\left.G=\frac{10.7 \cdot K_{1} \cdot q \cdot \psi}{K_{2} \cdot \eta \cdot\left[c_{3} \cdot T_{3}+H H V_{\text {gas }} \cdot \eta_{f}+\left(k_{1}+k_{2}\right) \cdot \rho_{2} \cdot\left[T_{2} \cdot c_{2}+\left(r+c_{4} \cdot T_{2}\right) d_{0}\right]\right.}\right],
$$




$$
\left.C_{\text {gas }}=\frac{(1.07 \cdot q \cdot m) \cdot \psi \cdot 10^{-2} \cdot \Delta W}{\tau \cdot \eta \cdot\left[\left(c_{3} \cdot T_{3}+H H V_{g a s} \cdot \eta_{f}\right)+\left(k_{1}+k_{2}\right) \cdot \rho_{2} \cdot\left[T_{2} \cdot c_{2}+\left(r+c_{4} \cdot T_{2}\right) d_{0}\right]\right.}\right],
$$

Setting the values of such parameters as: quantity of heat $q$, that is needed to evaporate moisture from grain by $\Delta W=5.5 \%$ (determined by Mollier h-x diagram of wet air in $\mathrm{kJ} \cdot \mathrm{kg}^{-1}$ ); dryer heat consumption irregularity coefficient during the grain drying cycle $\psi=0.8-1.05$ (depends on gasification process stability); coefficient $K_{1}$, that depends on $\mathrm{CO}, \mathrm{CO}_{2}, \mathrm{CH}_{4}$ content in producer gas, $K_{1}=17.62-19.4$ [9]; coefficient $K_{2}$, that shows carbon quantity in gas compared to its initial quantity in fuel considering all its loses $K_{2}=24.8-38.7$ [9]; dryer $\mathrm{CoP} \eta=0.7$; dryer furnace $\mathrm{CoP} \eta_{f}=0.85$; grain mass $m$, that needs drying; coefficients $k_{1}=1.57-1.74$ and $k_{2}=10.28-10.96$, that consider air quantity needed to burn producer gas and form drying media respectively [9]; specific producer gas heat capacity $c_{3}=1.05 \mathrm{~kJ} \cdot\left(\mathrm{m}^{3} \cdot \mathrm{K}\right)^{-1}$; producer gas temperature $T_{3}=673-873^{\circ} \mathrm{K}$; specific steam heat capacity $c_{4}=2.2 \mathrm{~kJ} \cdot(\mathrm{kg} \cdot \mathrm{K})^{-1}$; higher heating value of gas $H H V_{\text {gas }}=f\left(W_{\text {straw }}\right), \mathrm{kJ} \cdot\left(\mathrm{m}^{3}\right)^{-1}$ the dependence of specific straw consumption $G$ in $\mathrm{kg} \cdot(\text { ton } \%)^{-1}$ for grain drying was built, Fig. 3.

The investigations let us theoretically substantiate the working process of drying grain in pseudofluidized layer with intermittent drying media supply in a dryer working on producer gas. Technological parameters of the dryer are: drying capacity $-1.3-2 \mathrm{t} \cdot \mathrm{h}^{-1}$; time to reduce the moisture content from $19 \%$ to $13.5 \%-10-13 \mathrm{~min}$.; gas productivity of gasifier $P_{\text {gas }}=120-136 \mathrm{~m}^{3} \cdot \mathrm{h}^{-1}$ (for dryer drying capacity $2 \mathrm{t} \cdot \mathrm{h}^{-1}$ ) when using straw with $8 \ldots 30 \%$ moisture content. The paper dedicated to gasifier design development for the grain dryer is [9].

The investigation was made by multifactor experiments. Design of a proposed dryer, Fig. 1a, Fig. 1b, equipped with the gasifier, Fig. 1c, features pseudofludizing grain material not by the whole drying surface, but gradually by sections. In every moment of time grain is blow through with hot air on one part of the drying zone. Here it appears in pseudofluidized state. An intense drying is held and a wave is created that helps transporting grain along the drying chamber. At the same time the rest of grain stays in calm state. Heat redistributes equally within the layer as well as moisture redistributes inside each grain moving from inner to outer layers by capillaries.
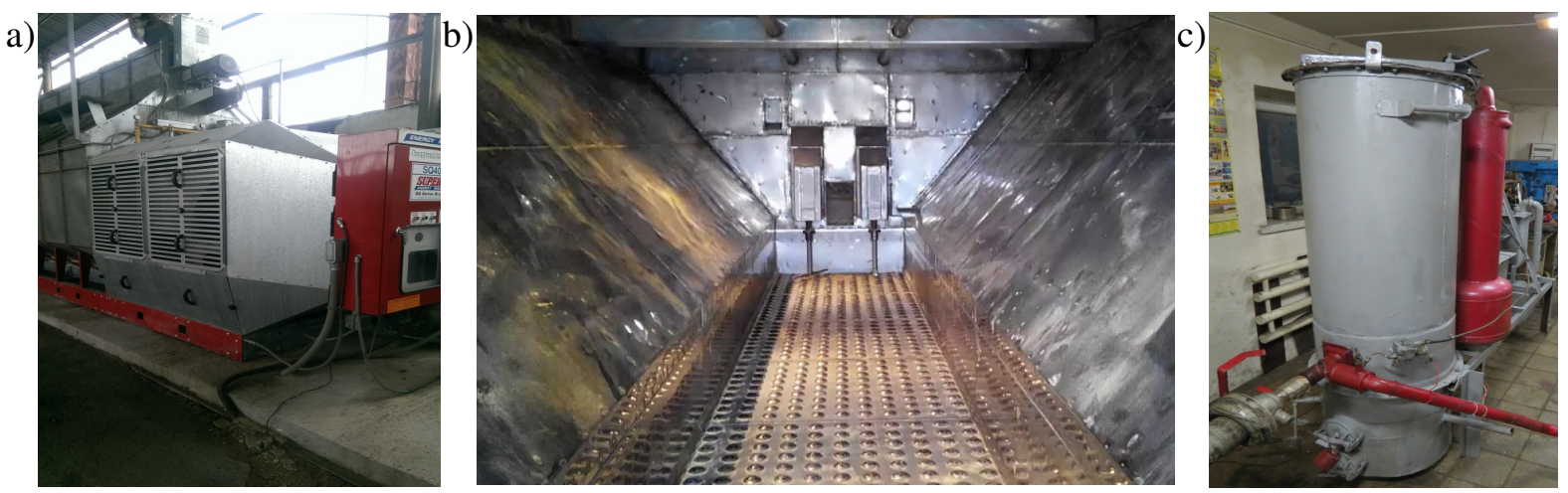

Fig. 1. Grain dryer (a), dryer working zone (b) and gasifier (c) views

Drying media temperature was measured with K-type thermocouple, installed in the gas distributor chamber, Fig. 1b. Grain temperature was measured with the method $[21 ; 22]$ measuring temperature of a suddenly released layer (after stopping drying media supply). Namely, it was measured, when grain was in the calm period by putting in a thermocouple into the grain layer $(3 \ldots 4$ points). Initial and final moisture content was measured with a moisturemetre Aqua-15 Etalon, and evaporated moisture was controlled with electronic laboratory scales AXIS ADGS. Anemometer GM18 is used to meashure the air flow velosity. The velocity of drying media was measured at the entrance (in the gas distribution chamber) and at the outlet - in the recirculation channel, then the values were averaged.

The goals of the investigation were to determine the optimal blowing period $\tau$ to the calm period ratio $\tau$ ' in the dryer, equiped with a gasifier, and to determine the optimal drying media temperature that provides the fastest grain moisture evaporation tempo. The grain should not be heated above maximum permissible temperature $T_{1}=50^{\circ} \mathrm{C}[21 ; 23]$. 
The variable factors of the experiment were: drying media temperature $T_{2}$, number of sections of grates of the dryer $n$ and grates' opening period $\tau$. The mentioned parameters were changing between limits: $T_{2}$ from 30 to $54{ }^{\circ} \mathrm{C} ; n$ from 4 to 16 ; $\tau$ from 10 to $50 \mathrm{~s}$. Factors coding were: $X_{1}=T_{2}, X_{2}=n$, $X_{3}=\tau$. To receive process models in form of quadratic polynomial a Box-Behnken type quadratic plan was used $[22 ; 23]$. For experimental data certainty repetition of experiments under the same conditions equals $k=3$. Eight original experiments were made according to the planning matrix and polynomial's linear part coefficients were calculated according to [22]. The values of the model relative error for all experiments according the plan of the multifactor analysis are lower than $3 \%$ [22]. The values of mean relative deviation are lower than $2.11 \%$ [22]. As it can be seen, the relative error values less than $10 \%$ are considered acceptable in modelling of the drying process [22]. Therefore, it can be concluded that the presented model predicts drying processes with a high accuracy.

\section{Results and discussion}

After calculating the correlation polynomial coefficients regression equations for drying exposition $\tau(7)$ and temperature increment $\Delta T_{1}(8)$ were received:

$$
\tau=5280-186.02 \cdot T_{2}+168.5 \cdot n-30.42 \cdot \tau^{\prime}-3.33 \cdot T_{2} \cdot n-0.134 \cdot n \cdot \tau^{\prime}+2.2 \cdot T_{2}^{2}+6.21 \cdot n^{2},
$$

Equation adequacy characteristics are: $R^{2}=0.985 ; F=19.03 ; p=1.88 \cdot 10^{-3}$.

$$
\begin{gathered}
\Delta T_{1}=20.66+0.08 \cdot T_{2}-0.0375 \cdot n+0.025 \cdot \tau^{\prime}-0.07 \cdot T_{2} \cdot n+0.062 \cdot T_{2} \cdot \tau^{\prime}+ \\
+0.07 \cdot n \cdot \tau^{\prime}-0.034 \cdot T_{2}^{2}+0.017 \cdot n^{2}-0.025 \cdot\left(\tau^{\prime}\right)^{2}
\end{gathered}
$$

Equation adequacy characteristics are: $R^{2}=0.99 ; F=18.3 ; p=2.03 \cdot 10^{-3}$.

The surfaces, Fig. 2a, and equation (7) analysis shows that while drying the media temperature lowers, drying exposition rises. It gains minimum with minimal sections number. The coefficients of the equation (7) show that among the linear terms of the equation, the drying media temperature $T_{2}$ and the number of sections $n$ have the greatest influence on the optimization parameter $\tau$. Grates' opening period $\tau$ and combination of the parameters $T_{2} \cdot n$ have less influence on this parameter. Equation analysis (7) shows that while the grates' opening period $\tau$ decreases the drying exposition $\tau$ rises. According to equation analysis (8) grain has higher temperature, if the drying media has higher temperature and it rises when the blowing time $\tau$ ' rises. Grain temperature increment is the lowest for the number of sections 13-16, Fig. $2 b$.

Therefore, a program was written to make optimization of polynomials (7) and (8). Investigations showed that for the drying media temperature of $60^{\circ} \mathrm{C}$ the drying process proceeds with the highest tempo between the sections 6 to 10. On practice, maximum productivity is reached with maximum grain material drying tempo and when the number of sections equals 14.

Drying process kinetic dependencies were developed experimentally. Following them, depending on initial grain moisture content, we can define the optimal drying time. This index was found for the design dryer by the method of checking all combinations of the experimental data by means of "Statistics 10 " software by the calm period $\tau$ " to blow through the period $\tau$ ratio. The calm period was $\tau^{\prime \prime}=\tau^{\prime} \cdot n-\tau$. The highest drying tempo was achieved for $\tau^{\prime \prime} \cdot(\tau)^{-1}$ ratio values 0 to 8 depending on the drying media temperature. Also we observed lowering moisture evaporation tempo from the grain layer with further drying media temperature rising. This regularity is explained by the phenomenon of grain quenching under high drying media temperature that makes moisture evaporation from the grain surface difficult.

Analyzing the experimental data we see that the grain dryer productivity was rising, while the drying media temperature was rising till $60^{\circ} \mathrm{C}$, but then it was lowering. Maximum dryer productivity at drying media temperature $60^{\circ} \mathrm{C}$ was reached for $\tau^{\prime \prime} \cdot(\tau)^{-1}=1: 13$ ratio. Thus, the highest drying tempo and productivity are reached for different $\tau^{\prime \prime} \cdot(\tau)^{-1}$ values, nevertheless, it should be admitted that, when rising the number of sections, the productivity rises sharply, though the moisture evaporation tempo lowers. 
a)

Drying exposure at $\mathrm{T}_{2}=30^{\circ} \mathrm{C}$

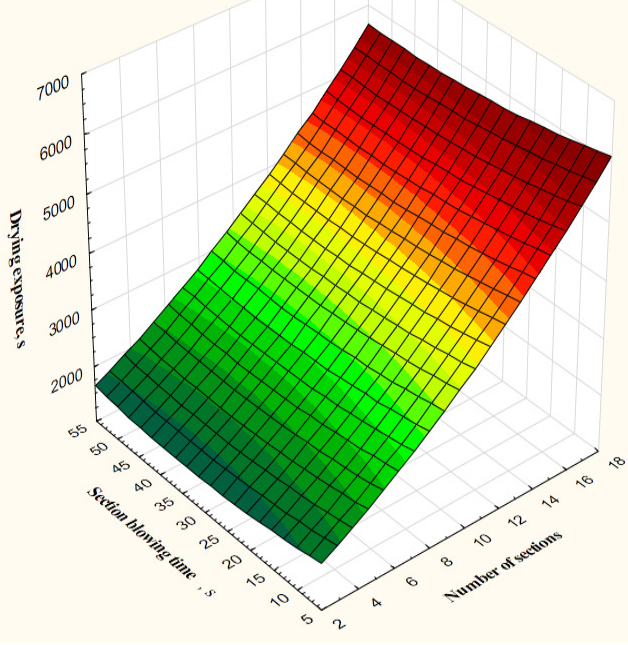

Drying exposure at $T_{2}=42^{\circ} \mathrm{C}$

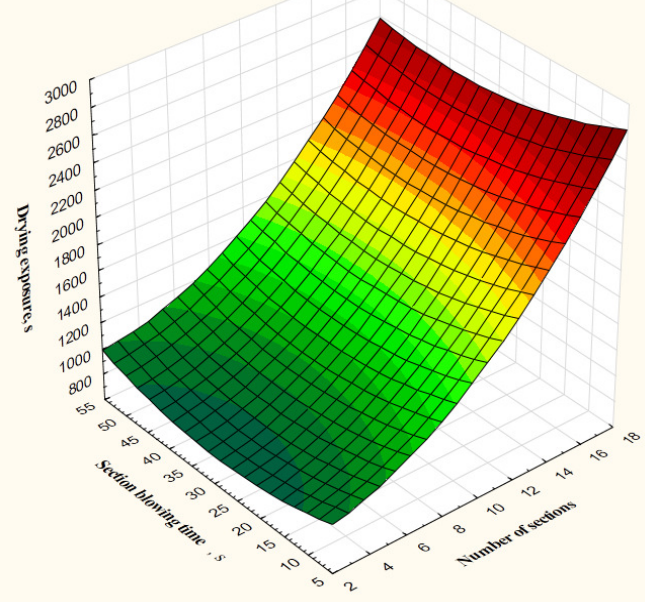

Drying exposure at $\mathrm{T}_{2}=54^{\circ} \mathrm{C}$

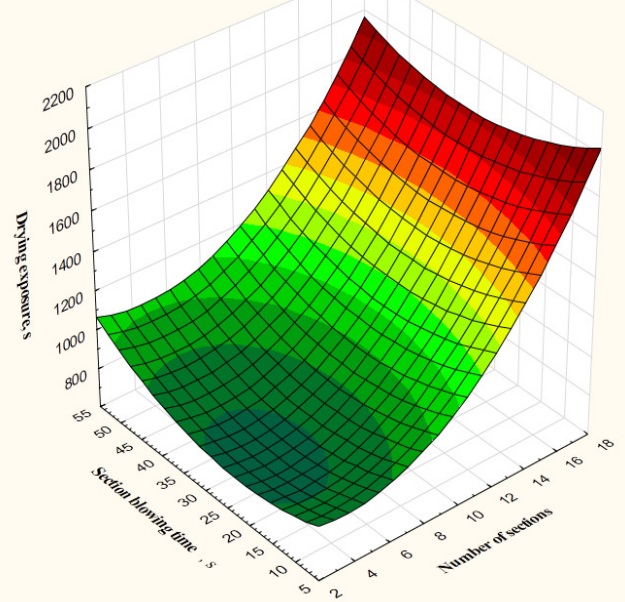

b)

Heating exposure at $T_{2}=30^{\circ} \mathrm{C}$
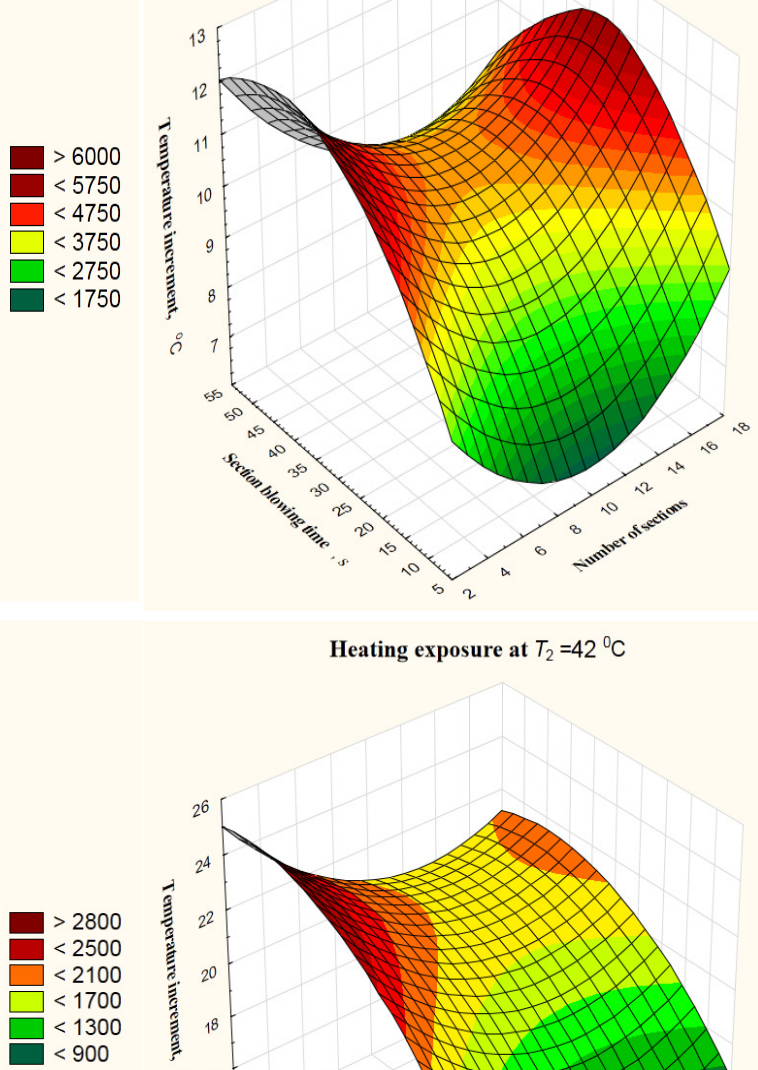

Heating exposure at $T_{2}=42{ }^{\circ} \mathrm{C}$

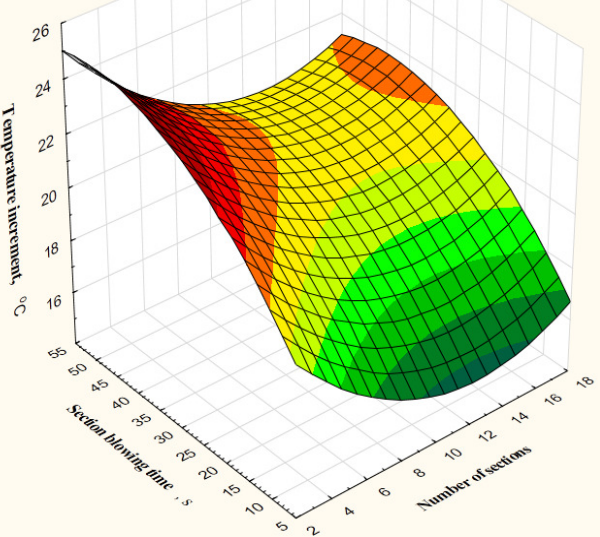

Heating exposure at $T_{2}=54{ }^{\circ} \mathrm{C}$

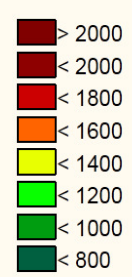

Fig. 2. Grain drying (a) and heating (b) exposition against number of sections and blowing trough time for different $T_{2}$ values 
So, the grain dryer was designed and made by maximum productivity criteria that were obtained experimentally with such rational values of the parameters: $T_{2}=60^{\circ} \mathrm{C}, n=14, \tau=30 \mathrm{~s}$. Technicaleconomical specifications of the dryer are as follows: drying capacity $1.5 \mathrm{t} \cdot \mathrm{h}^{-1}$; initial grain moisture content $-19 \%$, final moisture content $-13.5 \%$; drying media temperature $60{ }^{\circ} \mathrm{C}$; drying exposition $12 \mathrm{~min}$; drying media supply $-2600 \mathrm{~m}^{3} \cdot \mathrm{h}^{-1}$; fuel consumption (chopped straw) $50-56 \mathrm{~kg} \cdot \mathrm{h}^{-1}$ specific energy consumption $-4.28 \cdot 10^{6} \mathrm{~J} \cdot \mathrm{kg}^{-1}$. This dryer with gas feeding is made at "Vibroseparator" plant.

Experiments on using gasifier technologies for feeding the grain dryer show that specific consumption of chopped straw $G$ for drying grain depends greatly on its moisture content $W_{\text {straw }}$. Rising the straw moisture content by $5 \%$ leads to lowering the dryer specific productivity by $18-20 \%$. So, rational straw moisture content range is $W_{\text {straw }}=10-30 \%$. When using straw with the moisture content more than $30 \%$, the dryer specific productivity lowers by $25-30 \%$, thereby using gasifier technologies is inappropriate. Comparing the designed dryer with similar type dryers $[4 ; 5 ; 12 ; 23]$ we can see that this dryer not only fulfils the necessary grain drying technological modes, but also provides high indexes of economical, energetic and ecological effectiveness.

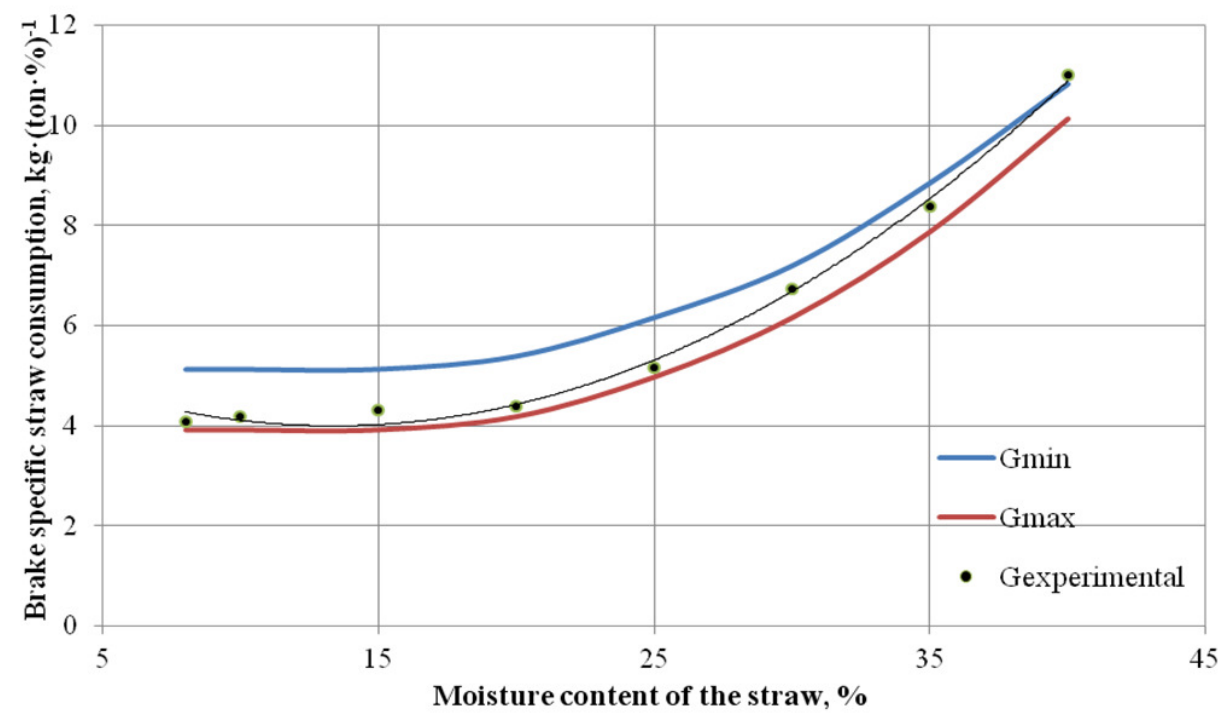

Fig. 3. Specific chopped straw consumption $G$ for grain drying process against straw moisture content $W_{\text {straw }}$

\section{Conclusions}

The experimental study, mathematical modelling and numerical simulation of the grain drying process in the dryer with pseudofluidized bed working on producer gas have led to the following conclusions.

1. A mathematical model of a convective grain drying process in pseudofluidized layer is proposed. It was developed on the basis of material and heat balance of the dried product and drying media. Yet, this model needs further development, because it does not fully take into account the possible movement of separate grains inside the layer, temperature ratio between the drying media inside the grain volume and outside of it, heat loses for unorganized air exchange.

2. With help of multifactor experiments with further data analysis a rational design and technological parameters of the designed dryer were set up: maximum dryer productivity $1.5 \mathrm{t} \cdot \mathrm{h}^{-1}$ is reached, when the drying media temperature is $60^{\circ} \mathrm{C}$; number of sections is 14 with blowing time of one section $30 \mathrm{~s}$; drying media supply $-2600 \mathrm{~m}^{3} \cdot \mathrm{h}^{-1}$; fuel consumption (straw) $50-56 \mathrm{~kg} \cdot \mathrm{h}^{-1}$; specific energy consumption $-4.28 \cdot 10^{6} \mathrm{~J} \cdot \mathrm{kg}^{-1}$.

3. Using gasifier technologies to supply grain dryers is expedient and provides high indexes of economical, energetic and ecological effectiveness, when using straw with the moisture content range of $10 \ldots 30 \%$. Raising the straw moisture content by $5-10 \%$ leads to additional heat consumption to evaporate this moisture by $7-15 \%$. Using straw with the moisture content above $30 \%$ lowers the specific dryer productivity by $25-30 \%$.

4. Using this dryer lowers the specific expenses on after harvesting post processing up to $30 \%$. 


\section{References}

[1] Марченко В. Що потрібно знати, щоб висушити зерно (What you must know to dry the grain). Agroexpert, № 9, 2016. (In Ukrainian). [online] [12.09.2016]. Available at: https://www.agroexpert.ua/ru/so-potribno-znati-sob-visusiti-zerno

[2] Hovmand S. Fluidized bed drying. Handbook of Industrial Drying. Mujumdar A.S. (Ed.). New York: CRC press, 1995, pp. 195-248.

[3] $\mathrm{Xu}$ B. H., Yu A. B. Numerical simulation of the gas-solid flow in a fluidized bed by combining discrete particle method with computational fluid dynamics. Chemical Engineering Science, vol. 52, Issue 16, 1997, pp. 2785-2809.

[4] Hou Q. F., Zhou Z. Y., Yu A. B. Micromechanical modelling and analysis of different flow regimes in gas fluidization. Chemical Engineering Science, vol. 84, 2012, pp. 449-468.

[5] Torrez Irigoyen R. M., Giner S. A. Drying-toasting kinetics of presoaked soybean in fluidised bed. Experimental study and mathematical modelling with analytical solutions. Journal of Food Engineering, vol. 128, 2014, pp. 31-39.

[6] Мухлев И.П., Сажин Б.С., Фролов В.Ф. Расчеты аппаратов кипящего слоя: Справочник (Calculations of fluidized bed apparatus: Handbook). Leningrad: Chemistry, 1986, 352 p. (In Russian).

[7] Syahrul S., Hamdullahpur F., Dincer I. Thermal analysis in fluidized bed drying of moist particles. Applied Thermal Engineering, vol. 22, Issue 15, 2002, pp. 1689-1776.

[8] Golub G.A., Kukharets S.M., Yarosh Y.D., Kukharets V.V. Integrated use of bioenergy conversion technologies in agroecosystems. INMATEH - Agricultural Engineering, vol. 51, No. 1, 2017, pp. 93-100.

[9] Tsyvenkova N.M., Golubenko A.A., Kukharets S.M., Biletsky V.R. The research of downdraft gas producer heat productivity on straw. Proceedings of International symposium "ISBINMA TEH Agricultural and Mechanical Engineering", October 27-29, 2016, Bucharest, Romania, pp. 83-91.

[10]Barmina I., Valdmanis R., Zake M., Ozola L., Strautins Ul. Development of gasification/combustion characteristics at thermo-chemical conversion of biomass mixtures. Proceedings of $16^{\text {th }}$ International Scientific Conference "Engineering for Rural Development", May 24-26, 2017, Jelgava, Latvia, pp. 54-59.

[11] Müller M., Heidenreich S., Foscolo P. Advanced Biomass Gasification. New Concepts for Efficiency Increase and Product Flexibility. Elsevier: "Academic Press", 2016. 140 p.

[12] Khanali M., Giglou A. Kh., Rafiee Sh. Model development for shelled corn drying in a plug flow fluidized bed dryer. Engineering in Agriculture, Environment and Food, vol. 11, Issue 1, 2018, pp. 1-8.

[13] Azmir J., Hou Q., Yu A. Discrete particle simulation of food grain drying in a fluidised bed. Powder Technology, vol. 323, 2018, pp. 238-249.

[14] Jajcevica D., Siegmanna E., Radekea Ch., Khinastab J.G. Large-scale CFD-DEM simulations of fluidized granular systems. Chemical Engineering Science, vol. 98, 2013, pp. 298-310.

[15] Hou Q.F., Zhou Z.Y., Yu A.B. Computational of heat transfer in a bubbling fluidized bed with a horizontal tube. AIChE journal, vol. 58, Issue 5, 2012, pp. 1422-1434.

[16] Aboltins A. Mathematical model of deep-bed grain layer drying by ventilation. Progress in industrial mathematics at ECMI 96. B. G. Teubner Stuttgart, 1997, pp. 143-149.

[17] Aboltins A. Theoretical study of material drying coefficient, Proceedings of $12^{\text {th }}$ International Scientific Conference "Engineering for Rural Development", May 23-24, 2013, Jelgava, Latvia, pp. 153-158.

[18] Sun Da-Wen, Woods J. L. Deep-bed simulation of the cooling of stored grain with ambient air: a test bed for ventilation control strategies. Journal of Stored Products Research, vol. 33, Issue 4, 1997, pp. 299-312.

[19] Sun Y., Pantelides C.C., Chalabi Z. S. Mathematical modelling and simulation of near-ambient grain drying. Computers and Electronics in Agriculture, vol. 13, Issue 3, 1995, pp. 243-271.

[20]Ziegler Th., Richter I.-G. Analysing deep-bed drying based on enthalpy-water content diagrams for air and grain. Computers and Electronics in Agriculture, vol. 26, Issue 2, 2000, pp. 105-122.

[21] Малин Н.И. Энергосберегающая сушка зерна (Energy-saving grain drying). Moscow: Kolos, 2004, 240 p. (In Russian). 
[22] Мельников С.В., Ацелкин В.Р., Рощин П.М. Планирование эксперимента в исследованиях сельскохозяйственных процессов (An experiment planning in researches of agricultural processes). Leningrad: Kolos, 1980, 168 p. (In Russian).

[23] Fesenko A.V. Optimization of technological and design parameters of a grain dryer with a fluidized bed. Collection of scientific papers of LNAU, Series: Technical sciences, № 42(54), 2004, pp. 150-153. 